\title{
The prevalence of hyperglycaemia and its relationship with mortality, readmissions and length of stay in an older acute surgical population: a multi-centre study
}

Running head: Prevalence \& Impact of Hyperglycaemia in Older Surgical Patients Phyo Kyaw Myint ${ }^{1,2}$, Stephanie Owen ${ }^{3}$, Lyndsay Pearce ${ }^{4}$, Matthew F Greig ${ }^{2}$, Hui Sian Tay $^{2}$, Caroline McCormack², Kathryn McCarthy ${ }^{5}$, Susan J Moug ${ }^{6}$, Michael J Stechman $^{7}$, Jonathan Hewitt ${ }^{3}$ : on behalf of Older Persons Surgical Outcomes Collaboration (OPSOC)

${ }^{1}$ AGEING; Epidemiology Group, Institute of Applied Health Sciences, University of Aberdeen, Aberdeen, UK

${ }^{2}$ Department of Medicine for the Elderly; Aberdeen Royal Infirmary, Aberdeen, UK ${ }^{3}$ University Hospital Llandough, Cardiff, UK

${ }^{4}$ Department of General Surgery; Manchester Royal Infirmary, Manchester, UK

${ }^{5}$ Department of General Surgery; North Bristol NHS Trust, Bristol, UK

${ }^{6}$ Department of General Surgery; Royal Alexandra Hospital, Paisley, Greater

Glasgow, UK

${ }^{7}$ Department of General Surgery; University Hospital of Wales, Cardiff, UK

\section{Correspondence to:}

Dr Jonathan Hewitt

Clinical Senior Lecturer

University Hospital Llandough

Cardiff

CF642XX, UK

Tel: +44 777961450 Fax: +44 2920711267

Mail to: hewittj2@cardiff.ac.uk 


\section{Funding statement}

This research received no specific grant from any funding agency in the public, commercial or not-for-profit sector.

\section{Competing Interests Statement}

None for all authors

\section{Contributorship statement}

All authors fulfil the criteria for authorship as per ICMJE guidelines.

\section{Bullet points}

- Hyperglycaemia was common on admission in older acute surgical population - $7.8 \%$ for all patients and $4.0 \%$ for those who were not previously known to have diabetes

- Only $71.3 \%$ of patients had their blood glucose checked on admission and this presents a potential missed opportunity for diagnosis

- Hyperglycaemia was not associated with any measured poor outcomes in this study (mortality, length of stay, readmission) but this may be due to a type 2 error

\section{Research questions}

- What is the prevalence of admission hyperglycaemia in older acute surgical patients?

- What is the impact of hyperglycaemia on 30- and 90-day mortality outcomes in these patients?

- Does admission hyperglycaemia linked to hospital readmission within 30 days and length of acute hospital stay? 


\section{Abstract}

Background: The purpose of the study is to examine the prevalence of hyperglycaemia in an older acute surgical population and its effect on clinically relevant outcomes in this setting.

Methods: Using Older Persons Surgical Outcomes Collaboration (OPSOC) multicentre audit data 2014, we examined the prevalence of admission hyperglycaemia, and its effect on 30- and 90-day mortality, readmission within 30 days and length of acute hospital stay using logistic regression models in consecutive patients, $\geq 65$ years, admitted to five acute surgical units in the UK hospitals in England, Scotland and Wales. Patients were categorised in three groups based on their admission random blood glucose: $<7.1$, between 7.1 and 11.1 , and $\geq 11.1 \mathrm{mmol} / \mathrm{L}$.

Results: A total of 411 patients (77.25 \pm 8.14 years) admitted during May \& June 2014 were studied. Only 293 patients (71.3\%) had glucose levels recorded on admission. The number (\%) of patients with a blood glucose $<7.1 \mathrm{mmol} / 1,7.1-$ $11.1 \mathrm{mmol} / 1$ and $\geq 11.1 \mathrm{mmol} / 1$ were 171(58.4), 99(33.8) and 23(7.8), respectively. On univariate analysis, admission hyperglycaemia was not predictive of any of the outcomes investigated. Although the characteristics of those with no glucose level were not different from the included sample, 30-day mortality was significantly higher in those who had not had their admission glucose level checked (10.2\% vs. 2.7\%) suggesting a potential type II error.

Conclusion: Despite current guidelines, nearly a third of older people with surgical diagnoses did not have their glucose checked on admission highlighting the challenges in prognostification and evaluation research to improve care of older frail surgical patients. 


\section{Introduction}

Abnormal glucose regulation occurs when people have diabetes or in times of acute illness. It results in high blood glucose levels (hyperglycaemia). Diabetes mellitus is the clinical condition present when glucose is chronically raised. It can remain undiagnosed in asymptomatic individuals (1) and is a risk factor for poor outcome following hospital admission (2). Hyperglycaemia is thus common in hospitalised patients, irrespective of diabetic status, (3) yet its prevalence in older surgical patients is unknown.

Although initially considered an advantageous response to physiological stress, (4) a relationship between admission hyperglycaemia and mortality is well established for critically ill patients. $(5,6)$ This association has been studied in the context of myocardial infarction, with significantly higher mortality rates reported amongst hyperglycaemic patients ( $8.4 \%$ vs. $2.4 \%, p<0.001)$. (7) Similar findings have also been described, for patients with Acute Coronary Syndrome, (8) Pneumonia, (9) and Stroke. (10) In addition, admission hyperglycaemia is associated with other poor outcomes, including increased length of hospital stay, hospital readmission, and increased risk of infection. $(11,12)$

Evidence suggests that the role of hyperglycaemia as a marker for poor outcomes extends further than its current application to critically ill patients. A prospective cohort study of 6,187 general medical and surgical patients identified admission hyperglycaemia as an independent predictor of mortality (hazard ratio 1.04 per 1.0 $\mathrm{mmol} / \mathrm{L}$ increase, 95\% confidence interval (CI) 1.02-1.06, $p=0.02$ ). (13) When considering an elective general surgical population, patients with preoperative random glucose levels of $5.6-11.1 \mathrm{mmol} / \mathrm{l}$ and $>11.1 \mathrm{mmol} / \mathrm{l}$ were 1.7 and 2.1 times more likely to die than those with a blood glucose $<5.6 \mathrm{mmol} / \mathrm{l}$. (14)

The prevalence of hyperglycaemia in an older acute surgical population specifically, and its effect on mortality has not been studied. Measuring blood glucose on admission to surgical units is a recommended procedure, $(15,16,17)$ however its role in surgical decision-making is not explicitly stated. (18) The global increase in ageing population means that the number of older people undergoing surgery is increasing at 
a rate faster than the rate of the overall population. (19) It is therefore important for us to establish factors that affect clinical outcomes in this population. Identifying patients with high mortality risk early on in admission can help establish an appropriate care pathway, direct hospital resources and ultimately reduce morbidity and mortality. (20) More recently, hyperglycaemia has also been discussed as a predictive factor for the development of subsequent type II diabetes, outlining further utility for admission screening. (21)

The purposes of this study therefore were (1) to establish the prevalence of admission hyperglycaemia in an older acute surgical patients, and (2) to examine its effect on 30- and 90-day mortality outcomes. Secondary purposes were to examine its relationship with hospital readmission within 30 days and length of acute hospital stay. 


\section{Methods}

As part of the Older Persons Surgical Outcomes Collaboration (OPSOC) http://www.opsoc.eu data were collected in five UK hospitals: (1) University Hospital of Wales, Cardiff, (2) North Bristol NHS Trust, Bristol, (3) Aberdeen Royal Infirmary, Aberdeen, (4) Royal Alexandra Hospital, Glasgow, and (5) Central Manchester Foundation Trust, Manchester. Together the study sites have a total catchment population of 2.5 million people. The cohort is comprised of all consecutive patients, $\geq 65$ years old, who presented to the acute general surgical unit of each study site throughout May and June 2014. This multicentre study aimed to audit the standard of diabetes care of older people in acute surgical units and thus we did not include acute surgical patients who were triaged to other speciality (usually acute geriatric medicine) but not transferred to acute surgical admission units. As an audit study with 3 month follow up data collection, we limited our baseline data collection for two month duration due to logistic reasons.

In order to describe the cohort, demographic data regarding age and gender were noted. The results from routine laboratory tests were recorded to characterise some co-morbidities. For example anaemia was defined as haemoglobin levels $<129 \mathrm{~g} / \mathrm{L}$, hypoalbuminaemia was defined as an albumin $<35 \mathrm{~g} / \mathrm{L}$ and polypharmacy was defined as a patient using $\geq 5$ medications on admission. The Canadian Study of Health and Ageing (CSHA) frailty scale was used to characterise patients on a scale of 1 (very fit), to 7 (severely frail) (see Appendix 1). (22) Multimorbidity, defined as the coexistence of $\geq 2$ chronic diseases (see Appendix 2). (23,24) Admission random blood glucose was measured via a finger prick test with the use of a glucometer. While glucose is a continuous variable and it should be treated as such, in this paper we have deliberately chosen the universally accepted cut off points for the diagnosis of impaired glucose tolerance and diabetes for the following reasons. As an audit study the focus was on categorical data collection so as to identify (1) proportion of patients who had their glucose checked; (2) the proportion of patients whose glucose levels were borderline hyperglycaemia or hyperglycaemia in cases where the levels were checked, and to assess whether this is associated with the selected outcomes. 
For the purpose of quantifying effects on outcomes, patients were categorised into three groups based on admission blood glucose level: $<7.1 \mathrm{mmol} / \mathrm{l}, 7.1-11.1 \mathrm{mmol} / \mathrm{l}$ and $\geq 11.1 \mathrm{mmol} / 1$. The diabetic status of each patient was established through medical notes and drug charts.

Follow-up data were collected using the in-hospital Clinical Portal Systems. Survival status was recorded at both 30 and 90-days following admission. Additionally, readmission to the hospital within 30-days of discharge was noted. The total length of hospital stay for each individual was calculated as whole day integers, rounded up to the nearest day.

This study involved the analysis of existing data only and all participants were service users. As such, this study was deemed a service evaluation using multicentre-audit approach and thus ethical approval was not required. All participating sites acquired institutional approvals at respective sites.

Statistical Analysis

Mean (SD) or median (IQR) for continuous and number (\%) for categorical data were reported as appropriate. Chi-squared and Fisher's exact tests were used to compare the baseline characteristics amongst the three blood glucose groups. Binary logistic regression was used to calculate odds ratios for mortality and hospital readmission using admission blood glucose levels of $<7.1 \mathrm{mmol} / \mathrm{l}, 7.1-11.1 \mathrm{mmol} / \mathrm{l}$ and $\geq 11.1 \mathrm{mmol} / \mathrm{l}$ as the predictor variables. The mean length of hospital stay was also compared amongst these groups using a one-way analysis of variance test (ANOVA). Kruskal-Wallis test was used for non-normally distributed variables. Statistical analyses were performer using STATA version 13.0. 


\section{Results}

In all 411 patients aged 65 years or older were studied. The mean (SD) age was 77.3 (8.1) years and 212 (51.6\%) were women. Frailty, defined as a CSHA score of five or greater, was present in 113 (27\%). Five or medications were used by 279 (67.9\%) and multimorbidity, defined as two or more co-morbid conditions was present in 304 (74\%). Other biomarkers consistent with frailty were also prevalent; with anaemia found in 183 (44.5\%) and hypoalbuminaemia in 171 (41.6\%). Seventy-nine patients (19.2\%) had diabetes. In two (0.5\%), the prior diabetes status was unknown. Of 330 patients with no previous history of diabetes a third $(n=109)$ did not have their glucose measured at the time of admission. In those who did undergo blood glucose measurement 9/221 (4.0\%) had an admission glucose value of $>=11.1 \mathrm{mmol} / \mathrm{L}$; the corresponding percentage of those with hyperglycaemia in patients with known diabetes was 14/71 (20.7\%). No glucose measurement was recorded in eight patients on admission.

Admission blood glucose data were available in only 293 individuals (71.3\%), the values ranged between 3.3-27.4mmol/L, with a mean value of 7.48 (S.D. 3.21) $\mathrm{mmol} / \mathrm{L}$. Baseline characteristics of the cohort with admission blood glucose data available were compared between three groups $(<7.1,7.1-11.0$ and $>=11.1 \mathrm{mmol} / \mathrm{L})$ (Table 1). Comparison of characteristics between those with available glucose data and those who had missing glucose data on admission did not show any significant differences (Supplementary Table 1). 171 (58.4\%) were normoglycaemic (random blood glucose $<7.1 \mathrm{mmol} / \mathrm{l}$ ). Twenty three (7.8\%) were hyperglycaemic (randomblood glucose $\geq 11.1 \mathrm{mmol} / 1)$. The remaining 99 (33.8\%) individuals had an admission blood glucose ranging between 7.1-11.1mmol/l. Individuals with an admission blood glucose $\geq 11.1 \mathrm{mmol} / 1$ had a significantly higher prevalence of known diabetes ( $\mathrm{P}<0.001$, Chi-squared test ). There were no other significant differences between the three blood glucose groups. 
Table 1: Distribution of sample characteristics among older acute surgical admissions by blood glucose categories

\begin{tabular}{|c|c|c|c|c|c|c|c|}
\hline \multicolumn{2}{|c|}{ Baseline Characteristic } & $\begin{array}{c}\text { Blood glucose } \\
\begin{array}{c}<7.1 \mathrm{mmol} / \mathrm{l} \\
\mathrm{N}=171\end{array}\end{array}$ & $\begin{array}{c}\text { Blood glucose } \\
7.1 \text { - 11mmol/ } \\
\text { N = } 99\end{array}$ & $\begin{array}{l}\text { Blood glucose } \\
\begin{array}{c}\geq 11.1 \mathrm{mmol} / \mathrm{l} \\
\mathrm{N}=23\end{array}\end{array}$ & \multicolumn{2}{|c|}{$N=293$} & $\mathbf{p}$ \\
\hline \multirow[t]{2}{*}{ Age } & & $77.6(8.3)$ & $77.2(8.2)$ & $74.4(7.8)$ & \multicolumn{2}{|c|}{$77.3(8.1)$} & \multirow{2}{*}{$p=0.21$} \\
\hline & & \multicolumn{5}{|c|}{ Mean )SD) } & \\
\hline & & \multicolumn{5}{|c|}{$N(\%)$} & \\
\hline \multirow[t]{2}{*}{ Sex } & Male & 78 (45.6) & $48(48.5)$ & 10 (43.5) & 136 & \multirow[b]{2}{*}{293} & \multirow{2}{*}{$p=0.86$} \\
\hline & Female & $93(54.4)$ & $51(51.5)$ & $13(56.6)$ & 157 & & \\
\hline \multirow{3}{*}{$\begin{array}{l}\text { Past Medical history } \\
\text { of Diabetes }\end{array}$} & Yes & $29(17.0)$ & $28(28.3)$ & $14(60.9)$ & 71 & \multirow{3}{*}{293} & \multirow{3}{*}{$p<0.001$} \\
\hline & No & $141(82.5)$ & $71(71.7)$ & $9(39.1)$ & 221 & & \\
\hline & Missing & $1(0.6)$ & $0(0.0)$ & $0(0.0)$ & 1 & & \\
\hline \multirow{3}{*}{$\begin{array}{l}\text { CSHA frailty score } \geq 5 \\
\text { 5) }\end{array}$} & Yes & $49(28.7)$ & 31 (31.3) & $5(21.7)$ & 85 & \multirow{3}{*}{293} & \multirow{3}{*}{$p=0.63$} \\
\hline & No & $121(70.8)$ & $67(67.7)$ & $18(78.3)$ & 206 & & \\
\hline & Missing & $1(0.5)$ & $1(1.0)$ & $0(0.0)$ & 2 & & \\
\hline \multirow{2}{*}{$\begin{array}{l}\text { Polypharmacy } \\
\text { (>5 medications) }\end{array}$} & Yes & $120(70.2)$ & $66(66.7)$ & 17 (73.9) & 203 & \multirow{2}{*}{293} & \multirow{2}{*}{$p=0.74$} \\
\hline & No & $51(29.8)$ & 33 (33.3) & $6(26.1)$ & 90 & & \\
\hline \multirow{2}{*}{$\begin{array}{l}\text { Anaemia } \\
(\mathrm{Hb}<129 \mathrm{~g} / \mathrm{l})\end{array}$} & Yes & $83(48.5)$ & 37 (37.4) & $7(30.4)$ & 127 & \multirow{2}{*}{293} & \multirow{2}{*}{$p=0.09$} \\
\hline & No & $88(51.5)$ & $62(62.6)$ & $16(69.6)$ & 166 & & \\
\hline \multirow[t]{2}{*}{ Multimorbidity } & Yes & $129(75.4)$ & 77 (77.8) & 17 (73.9) & 223 & \multirow{2}{*}{293} & \multirow[b]{2}{*}{$p=0.88$} \\
\hline & No & $42(24.6)$ & $22(22.2)$ & $6(26.1)$ & 70 & & \\
\hline \multirow[t]{2}{*}{$\begin{array}{l}\text { Hypoalbuminemia } \\
\text { (Albumin }<35 g / \text { ) }\end{array}$} & Yes & $81(47.4)$ & 38 (38.4) & $10(43.5)$ & 129 & \multirow{2}{*}{293} & \multirow[b]{2}{*}{$p=0.36$} \\
\hline & No & $90(52.6)$ & $61(61.6)$ & $13(56.5)$ & 164 & & \\
\hline \multirow[t]{3}{*}{ Operation } & Yes & 39 (22.8) & $18(18.2)$ & $6(26.1)$ & 63 & \multirow{3}{*}{293} & \multirow{3}{*}{$p=0.61$} \\
\hline & No & $128(74.9)$ & 78 (78.8) & 17 (73.9) & 223 & & \\
\hline & Missing & $4(2.3)$ & $3(3.0)$ & $0(0.0)$ & 7 & & \\
\hline
\end{tabular}


Supplementary Table 1: Characteristics comparison between those with and without admission blood glucose levels

\begin{tabular}{|c|c|c|c|c|c|c|}
\hline Baseline Charac & eristic & $\begin{array}{l}\text { Blood glucose } \\
\text { Not Missing } \\
\qquad N=293\end{array}$ & $\begin{array}{l}\text { Blood glucose } \\
\text { Missing } \\
\text { N = } 118\end{array}$ & \multicolumn{2}{|c|}{$N=411$} & Test Statistic \\
\hline \multirow[t]{3}{*}{ Age } & & $77.2(8.2)$ & $77.3(8.0)$ & 77.3 & (8.1) & \multirow{2}{*}{$p=0.93$} \\
\hline & & \multicolumn{4}{|c|}{ Mean (SD) } & \\
\hline & & \multicolumn{4}{|c|}{ N (\%) } & \\
\hline \multirow[t]{2}{*}{ Sex } & Male & $136(46.4)$ & $63(53.4)$ & 199 & \multirow{2}{*}{411} & \\
\hline & Female & 157 (53.6) & $55(46.6)$ & 212 & & $p=0.20$ \\
\hline \multirow{3}{*}{$\begin{array}{l}\text { Past Medical history } \\
\text { of Diabetes }\end{array}$} & Yes & $71(24.2)$ & $8(6.8)$ & 79 & \multirow{3}{*}{411} & \multirow{3}{*}{$p<0.001$} \\
\hline & No & $221(75.4)$ & 109 (92.4) & 330 & & \\
\hline & Missing & $1(0.3)$ & $1(0.8)$ & 2 & & \\
\hline \multirow{3}{*}{$\begin{array}{l}\text { CSHA frailty score } \\
\geq 5)\end{array}$} & Yes & 85 (29.1) & $28(23.7)$ & 113 & \multirow{3}{*}{411} & \multirow{3}{*}{$p=0.79$} \\
\hline & No & $206(70.3)$ & $89(75.4)$ & 295 & & \\
\hline & Missing & $2(0.7)$ & $1(0.9)$ & 3 & & \\
\hline \multirow{2}{*}{$\begin{array}{l}\text { Polypharmacy } \\
\text { (>5 medications) }\end{array}$} & Yes & 203 (69.3) & $76(64.4)$ & 279 & \multirow{2}{*}{411} & \multirow[b]{2}{*}{$p=0.40$} \\
\hline & No & $90(30.7)$ & $42(35.6)$ & 132 & & \\
\hline \multirow{2}{*}{$\begin{array}{l}\text { Anaemia } \\
(\mathrm{Hb}<129 \mathrm{~g} / \mathrm{l})\end{array}$} & Yes & 127 (43.3) & $56(47.5)$ & 183 & \multirow{2}{*}{411} & \multirow[b]{2}{*}{$p=0.52$} \\
\hline & No & 166 (56.7) & $62(52.5)$ & 228 & & \\
\hline \multirow[t]{2}{*}{ Multimorbidity } & Yes & 223 (76.1) & $81(68.6)$ & 304 & \multirow{2}{*}{411} & \multirow[b]{2}{*}{$p=0.15$} \\
\hline & No & 70 (23.9) & 37 (31.4) & 107 & & \\
\hline \multirow{2}{*}{$\begin{array}{l}\text { Hypoalbuminemia } \\
\text { (Albumin <35g/l) }\end{array}$} & Yes & $129(44.0)$ & $42(35.6)$ & 171 & \multirow{2}{*}{411} & \multirow[b]{2}{*}{$p=0.15$} \\
\hline & No & $164(56.0)$ & $76(64.4)$ & 240 & & \\
\hline \multirow[t]{3}{*}{ Operation } & Yes & 63 (21.5) & 16 (13.6) & 79 & \multirow{3}{*}{411} & \multirow{3}{*}{$p=0.08$} \\
\hline & No & 223 (76.1) & 101 (85.6) & 324 & & \\
\hline & Missing & $7(2.4)$ & $1(0.8)$ & 8 & & \\
\hline
\end{tabular}


With regard to the outcomes examined, 20 (4.9\%) patients died within 30-days of admission and only 8 patients who died had blood glucose measured (40\% of those who died). At 90-days, 1 patient was lost to follow-up, and of the remaining 410 individuals, 36 (8.8\%) died of whom 22 (61.1\%) had blood glucose data on admission. Readmission rates were recorded for all 411 patients, and 82 (20.0\%) were readmitted within 30-days of discharge. Length of hospital stay (LOS) was available for 400 (97.3\%) patients. The median LOS was 5.5 days with the Inter Quartile Range (IQR) of 3-10 days. Similarly, approximately half of those requiring re-admission or longer length of stay had missing glucose data.

Unadjusted odds ratios for the outcomes investigated based on admission blood glucose levels $(\mathrm{N}=293)$ are shown in Table 2. There were no significant associations evident between increasing admission blood glucose and any of the outcomes investigated. The only difference between the blood glucose groups in terms of baseline characteristics was the prevalence of diabetes (see Table 1). As blood glucose and diabetes are directly related it was not appropriate to calculate adjusted odds ratios for this variable.

Examination of distribution of missing blood glucose data by study site showed only one hospital had 100\% compliance with blood glucose measurement on admission for acute surgical patients. Failure to record this ranged between $30.1 \%$ and $48.1 \%$ in the other four sites. Odds ratios for each outcome, based upon whether or not patients had available blood glucose data showed no significant differences except 30-day mortality where the mortality rate in those without admission blood glucose level was higher $(\mathrm{P}=0.004)$ (Table 3). 
Table 2: Odds Ratios and their corresponding 95\% Confidence Intervals for study outcomes using admission glucose category of $<7.1 \mathrm{mmol} / \mathrm{L}$ as the reference group

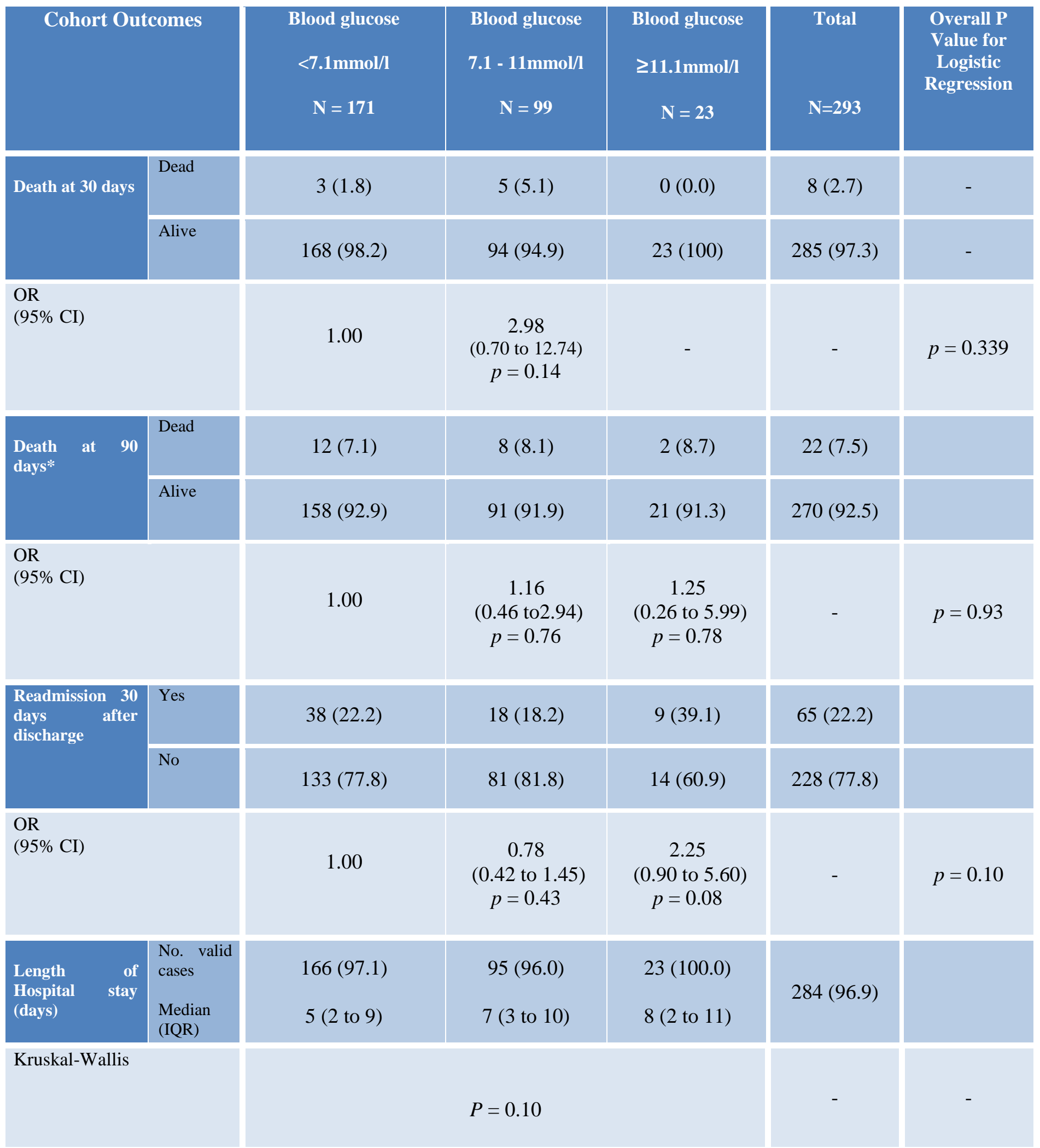


Table 3: Outcome comparison between those with and without admission blood glucose levels

\begin{tabular}{|c|c|c|c|c|}
\hline \multicolumn{2}{|l|}{ Cohort Outcomes } & Blood glucose & Blood glucose & Total \\
\hline & & $\mathrm{N}=293$ & $\mathrm{~N}=118$ & $\mathrm{~N}=411$ \\
\hline \multirow[t]{2}{*}{ Death at 30 days } & Dead & $8(2.7)$ & $12(10.2)$ & $20(4.9)$ \\
\hline & Alive & $285(97.3)$ & $106(89.8)$ & $391(95.1)$ \\
\hline \multicolumn{2}{|l|}{$\begin{array}{l}\text { OR } \\
(95 \% \mathrm{CI})\end{array}$} & \multicolumn{2}{|c|}{$\begin{array}{c}4.03 \\
(1.60 \text { to } 10.14) \\
p=0.004\end{array}$} & - \\
\hline \multirow[t]{2}{*}{ Death at 90 days } & Dead & $22(7.5)$ & $14(11.9)$ & $36(8.8)$ \\
\hline & Alive & $270(92.5)$ & $104(88.1)$ & $374(91.2)$ \\
\hline \multicolumn{2}{|l|}{$\begin{array}{l}\text { OR } \\
(95 \% \mathrm{CI})\end{array}$} & \multicolumn{2}{|c|}{$\begin{array}{c}1.65 \\
(0.82 \text { to } 3.35) \\
p=0.16\end{array}$} & - \\
\hline \multirow[t]{2}{*}{ Readmission 30 days after discharge } & Yes & $65(22.2)$ & $17(14.4)$ & $82(20.0)$ \\
\hline & No & $228(77.8)$ & $101(85.6)$ & $329(80.0)$ \\
\hline \multicolumn{2}{|l|}{$\begin{array}{l}\text { OR } \\
(95 \% \mathrm{CI})\end{array}$} & \multicolumn{2}{|c|}{$\begin{array}{c}0.59 \\
(0.33 \text { to } 1.06) \\
p=0.07\end{array}$} & - \\
\hline Length of Hospital stay (days) & $\begin{array}{l}\text { No. valid cases } \\
\text { Mean (SD) }\end{array}$ & $\begin{array}{l}284(96.9) \\
9.10(12.5)\end{array}$ & $\begin{array}{l}116(98.3) \\
9.72(11.6)\end{array}$ & $400(97.3)$ \\
\hline \multicolumn{2}{|l|}{ Independent samples t-test } & \multicolumn{2}{|c|}{$\begin{array}{c}(-3.27 \text { to } 2.04) \\
p=0.65\end{array}$} & - \\
\hline
\end{tabular}




\section{Discussion}

The prevalence of known diabetes in the cohort was high at $19.2 \%$. On admission blood glucose levels was recorded in just over two thirds of older people admitted with acute surgical diagnoses. This contrasts with the national guidelines' requirement of surgical services to test for diabetes status on admission to hospital (16 17). The prevalence of either borderline hyperglycaemia or hyperglycaemia was also high at $41.6 \%$ in those whom blood glucose levels were available. As expected, there was a higher prevalence of known diabetes amongst patients with admission hyperglycaemia $(p<0.001)$. When considering the 23 hyperglycaemic patients, 9 (39.1\%) did not have a prior diagnosis of diabetes, and the fact that observed 30-day mortality rates were significantly higher in those without glucose measurements compared with those in whom it was recorded illustrates potential challenges of caring for older surgical patients in the acute setting. Thus differential early survival rates might have influenced the results of the current study with regard to impact of hyperglycaemia on outcomes. The prevalence of diabetes was significantly higher amongst patients with available blood glucose values, compared with those without (24.2\% vs. 6.8\%, $p<0.001$ ). This suggests that individuals with a past medical history of diabetes were more likely to undergo blood glucose testing on admission. This may represent a missed opportunity in detecting undiagnosed or late onset diabetes.

This is the first study to investigate the prevalence of admission hyperglycaemia in an older acute surgical population and examine its effect on outcomes including mortality. Consequently, there are limited studies available with which to compare findings. In 1997, Dzankic et al. (18) conducted a prospective cohort study of 544 older surgical patients in a US setting to investigate the prevalence of hyperglycaemia and its predictive value on adverse outcomes in patients $\geq 70$ years (mean age 78 years), presenting for non-cardiac elective surgery. In contrast to this current report, pre-operative blood glucose was investigated as opposed to admission readings. They found a similar prevalence of hyperglycaemia (6.8\%) and in their study, abnormal preoperative glucose was not associated with postoperative mortality (OR 1.53, 95\% CI 0.51-4.55, $p=0.44)$. However, the fact that all patients studied were considered eligible for elective surgery implies that their cohort characteristics may be substantially different from current study in which only $19.2 \%$ of patients underwent 
surgery. Furthermore, for some of our cohort this would have been an emergency procedure and adverse outcomes are known to occur more frequently following emergency surgery. (25) Consequently, it would be difficult to directly compare outcomes amongst these varying cohorts of patients.

Sleiman et al. (26) also investigated the prevalence of hyperglycaemia and its role as a predictor of mortality in acutely ill older patients admitted to a sub-intensive (high dependency) care unit in Italy $(\mathrm{N}=1,115)$. Not surprisingly, the prevalence of diabetes in this setting was high at $28.8 \%$. When considering the 822 patients without known diabetes, 104 (12.7\%) had hyperglycaemia on admission. In contrast to our study, it was demonstrated that newly recognised hyperglycaemia $(\geq 10.0 \mathrm{mmol} / \mathrm{l})$ was independently associated with mortality (adjusted OR 2.7, 95\%CI 1.6-4.8). This may have been due to the fact that only non-diabetic patients were included in the analysis, and mortality rates amongst hyperglycaemic non-diabetic patients are known to be high. $(3,13,27,28)$ With a smaller sample, we were not able to make this distinction, and thus this relationship may have been concealed, furthermore, the high dependency setting implied a more unwell population thus a direct comparison with our study is problematic.

Additional studies have used lower random blood glucose cut off levels when establishing the prevalence of hyperglycaemia. Noordzij et al. (14) conducted a casecontrol study of general surgical patients in the Netherlands, in which an admission random blood glucose $<5.6 \mathrm{mmol} / \mathrm{l}$ was considered normal. Of the 2,151 patients with admission blood glucose data available, 829 (38.5\%) were normoglycaemic. This is considerably lower than the 171 (58.4\%) individuals defined as normoglycaemic when using a random blood glucose level of $<7.1 \mathrm{mmol} / \mathrm{l}$ in our study. Unlike our study, preoperative hyperglycaemia levels $\geq 11.1 \mathrm{mmol} / 1$ were associated with increased mortality (adjusted OR 2.1, 95\% CI 1.3-3.5; $p<0.001$ ). However, comparison with our study is again difficult due to the fact that the authors did not consider older patients specifically, but rather studied all surgical patients aged over 15 years.

To date, this is one of the first studies to establish the prevalence of hyperglycaemia specifically within an older acute surgical population. Its multi-centre design across five UK hospital sites, representing both urban and rural populations and significant 
total catchment population imply good generalisability to the UK population and should be representative of NHS health care provision. Each patient's diabetic status was established through analysis of medical notes and drug charts, which is generally accepted as a reliable data source.

Whilst our results highlight the current variation in routine clinical practice among different regional centres within the UK, an inherent limitation of this study with regard to examining the relationship between hyperglycaemia and outcome relationship was based on a subset of the study population with available admission glucose levels. The number of outcomes observed in the hyperglycaemia group were relatively small in those with available glucose data with a sample size of 293. It is likely to have affected our ability to detect any significant associations between admission hyperglycaemia and outcomes. This is demonstrated by the wide confidence intervals generated. It is possible that the non-significant findings are the result of a type II statistical error.

Identifying hyperglycaemia on admission regardless of diabetic status will aid patient care on a number of levels. There is increasing evidence to suggest that treatment of hyperglycaemia with insulin-based regimes is beneficial in reducing morbidity and mortality. (29) Additionally, screening provides an opportunity to identify patients with possible undiagnosed diabetes. (30) Further studies also describe an association between admission hyperglycaemia and 3-year type II diabetes risk, which increased from $<1 \%$ for a glucose $\leq 5 \mathrm{mmol} / 1$ to $15 \%$ at $15 \mathrm{mmol} / 1$. (21) This suggests that admission screening will identify patients at high risk of developing diabetes in the future, for whom health promotion strategies can be targeted. Furthermore, patients with available admission glucose levels might have been offered appropriate treatments for hyperglycaemia thus explaining 30-day mortality rates difference between two groups (see Table 3). This further highlights the fact that checking glucose at point of care might represent a valuable opportunity.

A substantial proportion of patients failed to receive an admission blood glucose test in accordance with current guidelines. $(15,16,17)$ Although, $89.9 \%$ of diabetic individuals did have blood glucose data available, this is sub-optimal. Similarly, it is concerning that $33.0 \%$ of non-diabetic individuals did not have blood glucose data 
recorded. The extent of missing data was not equally distributed amongst the hospital sites investigated. One site had blood glucose data available for $100 \%$ of patients, demonstrating that this is a feasible practice to achieve and highlights the variation in practices in surgical units. Variation in services and outcomes has been well recognised. Case mix adjustment taking into account individual prognostic indicators thus constitute as vital information in evaluation of performance of surgical units. Further, it is good clinical practice to adhere to clinical guidelines and our study highlights the challenges in prognostification and health services research involving older surgical patients. Therefore, efforts to improve compliance with blood glucose screening should therefore be a key implication for policy and practice.

The aim of this study was to establish the prevalence of hyperglycaemia in an older acute surgical population and this was achieved. However, one limitation was the failure to distinguish between stress hyperglycaemia and undiagnosed type II diabetes as the cause of hyperglycaemia in patients without diabetes. The role of glycosylated haemoglobin $\left(\mathrm{HbA}_{1 \mathrm{c}}\right)$ has been discussed in this context. $(31,32) \mathrm{HbA}_{1 \mathrm{c}}$ represents the average plasma glucose level haemoglobin is exposed to within its 90-day lifespan, and thus is far less influenced by acute illness (33). Since 2010, HbA1c has been a recognised method of diagnosing diabetes and testing in this context may prove useful. $\mathrm{HbA}_{1 \mathrm{c}}$ testing should be incorporated into future research to provide insight into the proportion of older surgical patients affected by these varying forms of hyperglycaemia and the influence they have on clinical outcomes.

While our analysis used categorical glucose levels hence reduced the statistical power, as an audit study the focus was on categorical data collection so as to identify (1) proportion of patients who had their glucose checked; (2) the proportion of patients whose glucose levels were borderline hyperglycaemia or hyperglycaemia in cases where the levels were checked, and to assess whether this is associated with the selected outcomes.

In summary, we found no significant association between hyperglycaemia and the outcomes examined although we were not able to exclude a type II error. Further research, involving a larger sample, is needed to verify these findings, perhaps utilising glycated HbA1c to differentiate between diabetes and stress hyperglycaemia. 
Establishing the underlying causes of hyperglycaemia would also be beneficial in gaining better understanding and deeper insight to current knowledge. Our study highlights the fact that a significant number of older acute surgical patients are not receiving blood glucose testing on hospital admission. Our results highlight the challenges in prognosis and health service evaluation research for benchmarking and quality improvement purposes in older acute surgical populations. Efforts should be made to increase admission blood glucose screening for older surgical patients, in accordance with current guidelines. 


\section{References}

1. Beagley J, Guariguata L, Weil C, Motala AA. Global estimates of undiagnosed diabetes in adults. Diabetes Research and Clinical Practice. 2014;103:150-60.

2. Nirantharakumar K, Hemming K, Narendran P, Marshall T, Coleman JJ. A Prediction Model for Adverse Outcome in Hospitalized Patients With Diabetes. Diabetes Care. 2013;36:3566-72.

3. Umpierrez GE, Isaacs SD, Bazargan N, You X, Thaler LM, Kitabchi AE. Hyperglycaemia: an independent marker of in- hospital mortality in patients with undiagnosed diabetes. The Journal of clinical endocrinology and metabolism. 2002;87:978.

4. Dungan KM, Braithwaite SS, Preiser J-C. Stress hyperglycaemia. The Lancet. 2009;373:1798-807.

5. Christiansen C, Toft P, Jorgensen H, Andersen S, Tonnesen E. Hyperglycaemia and mortality in critically ill patients. A prospective study. Intensive Care Medicine. 2003;29:154-8.

6. Falciglia M, Freyberg RW, Almenoff PL, Render ML, Alessio DA. Hyperglycaemia-related mortality in critically ill patients varies with admission diagnosis. Critical Care Medicine. 2009;37:3001-9

7. Ishihara M, Kagawa E, Inoue I, Kawagoe T, Shimatani Y, Kurisu S, et al. Impact of admission hyperglycaemia and diabetes mellitus on short- and longterm mortality after acute myocardial infarction in the coronary intervention era. American Journal of Cardiology. 2007;99:1674-9.

8. Timoteo AT, Papoila AL, Rio P, Miranda F, Ferreira ML, Ferreira RC. Prognostic impact of admission blood glucose for all-cause mortality in 
patients with acute coronary syndromes: added value on top of GRACE risk score. European heart journal Acute cardiovascular care. 2014;3:257-63.

9. Schuetz P, Friedli N, Grolimund E, Kutz A, Haubitz S, Christ-Crain M, et al. Effect of hyperglycaemia on inflammatory and stress responses and clinical outcome of pneumonia in non- critical- care inpatients: results from an observational cohort study. Diabetologia. 2014;57:275-84.

10. Kostulas N, Markaki I, Cansu H, Masterman T, Kostulas V. Hyperglycaemia in acute ischaemic stroke is associated with an increased 5-year mortality. Age and ageing. 2009;38:590.

11. Evans N, Dhatariya K. Assessing the relationship between admission glucose levels, subsequent length of hospital stay, readmission and mortality. Clinical Medicine. 2012;12:137-9.

12. Richards JE, Hutchinson J, Mukherjee K, Jahangir AA, Mir HR, Evans JM, et al. Stress hyperglycaemia and surgical site infection in stable nondiabetic adults with orthopedic injuries. Journal of Trauma and Acute Care Surgery. 2014;76:1070-5.

13. Cheung N, Li S, Ma G, Crampton R. The relationship between admission blood glucose levels and hospital mortality. Diabetologia. 2008;51:952-5.

14. Noordzij PG, Boersma E, Schreiner F, Kertai MD, Feringa HHH, Dunkelgrun $\mathrm{M}$, et al. Increased preoperative glucose levels are associated with perioperative mortality in patients undergoing noncardiac, nonvascular surgery. Eur J Endocrinol. 2007;156:137-42.

15. Umpierrez GE, Hellman R, Korytkowski MT, Kosiborod M, Maynard GA, Montori VM, et al. Management of Hyperglycaemia in Hospitalized Patients in Non-Critical Care Setting: An Endocrine Society Clinical Practice Guideline. Journal of Clinical Endocrinology \& Metabolism. 2012;97:16-38. 
16. Griffiths R, Beech F, Brown A, Dhesi J, Foo I, Goodall J, et al. Peri- operative care of the elderly 2014 Association of Anaesthetists of Great Britain and Ireland. Anaesthesia. 2014;69:81-98.

17. Diabetes UK. Management of adults with diabetes undergoing surgery and elective procedures: improving standards. 2011. [Accessed 22nd July 2015]. Available from: https://www.diabetes.org.uk/About us/What-wesay/Specialist-care-for-children-and-adults-andcomplications/Management-of-adults-with-diabetes-undergoing-surgeryand-elective-procedures-improving-standards/

18. Dzankic S, Pastor D, Gonzalez C, Leung JM. The prevalence and predictive value of abnormal preoperative laboratory tests in elderly surgical patients. Anesthesia and Analgesia. 2001;93:301-8.

19. Etzioni DA, Liu JH, Maggard MA, Ko CY. The aging population and its impact on the surgery workforce. Annals of Surgery. 2003;238:170-7.

20. Sebranek JJ, Lugli AK, Coursin DB, Hemmings HC. Glycaemic control in the perioperative period. British Journal of Anaesthesia. 2013;111:18-34.

21. McAllister D, Hughes K, Lone N, Mills N, Sattar N, McKnight J, et al. Stress Hyperglycaemia in Hospitalised Patients and Their 3- Year Risk of Diabetes: A Scottish Retrospective Cohort Study. Plos Medicine. 2014;11:20-5.

22. Rockwood K, Song X, MacKnight C, Mitnitski A, Bergman H, Hogan DB, et al. A global clinical measure of fitness and frailty in elderly people. CMAJ. 2005;173(5):489-95.

23. Charlson ME, Pompei P, Ales KL, MacKenzie CR. A new method of classifying prognostic comorbidity in longitudinal studies: Development and validation. Journal of chronic diseases. 1987;40:373-383 
24. Diederichs C, Berger K, Bartels DB. The measurement of multiple chronic diseases--a systematic review on existing multimorbidity indices. The Journals of Gerontology Series A, Biological Sciences and Medical Sciences. 2011;66:301.

25. Peden CJ, Peden MPW, Grocott MPW. National Research Strategies: What outcomes are important in peri- operative elderly care? Anaesthesia. 2014;69:61-9.

26. Sleiman I, Morandi A, Sabatini T, Ranhoff A, Ricci A, Rozzini R, et al. Hyperglycaemia as a predictor of in-hospital mortality in elderly patients without diabetes mellitus admitted to a sub-intensive care unit. Journal of the American Geriatrics Society. 2008;56:1106-10.

27. Candelise L, Landi G, Orazio EN, Boccardi E. Prognostic-Significance of Hyperglycaemia in Acute Stroke. Archives of Neurology. 1985;42:661-3.

28. Meier JJ, Deifuss S, Klamann A, Launhardt V, Schmiegel WH, Nauck MA. Plasma glucose at hospital admission and previous metabolic control determine myocardial infarct size and survival in patients with and without type 2 diabetes - The Langendreer Myocardial Infarction and Blood Glucose in Diabetic Patients Assessment (LAMBDA). Diabetes Care. 2005;28:2551-3.

29. Langley J, Adams G. Insulin- based regimens decrease mortality rates in critically ill patients: A systematic review. Diabetes/Metabolism: Research \& Reviews. 2007;1:184-92.

30. Department of Health. National Service Framework for Diabetes. 2001. [Accessed 29 ${ }^{\text {th }}$ April 2015]. Available from: https://www.gov.uk/government/uploads/system/uploads/attachment_data/file/ 198836/National_Service_Framework_for_Diabetes.pdf 
31. Greci LS, Kailasam M, Malkani S, Katz DL, Hulinsky I, Ahmadi R, et al. Utility of HbA1c Levels for Diabetes Case Finding in Hospitalized Patients With Hyperglycaemia. Diabetes Care. 2003;26:1064-8.

32. Farrokhi F, Smiley D, Umpierrez G. Glycemic control in non- diabetic critically ill patients. Best Practice \& Research: Clinical Endocrinology \& Metabolism. 2011;25:813-24.

33. World Health Organization. Use of Glycated Haemoglobin (HbA1c) in the Diagnosis of Diabetes Mellitus. 2011. [Accessed 29 April 2015]. Available from:

http://www.who.int/cardiovascular_diseases/report-hba1c_2011_edited.pdf 